\title{
Usutu Virus RNA in Mosquitoes, Israel, 2014-2015
}

\section{Batya Mannasse, Ella Mendelson, Laor Orshan, Orna Mor, Uri Shalom, Tamar Yeger, Yaniv Lustig}

We identified Usutu virus (USUV) RNA in 6 pools of mosquitoes trapped in northern Israel during 2014-2015. These Israeli strains were most similar to strains identified in Senegal and Germany, which further elucidates common ancestry and evolutionary dynamics of USUV. Our findings suggest that human infection with USUV might occur in Israel.

$\mathrm{U}$ sutu virus (USUV) is a vectorborne flavivirus first isolated in South Africa in 1959 (1). The reservoirs for USUV, which are similar to those for West Nile virus (WNV), include numerous species of birds, and it is transmitted primarily by Culex spp. mosquitoes (2). Circulation of USUV has been reported in several countries in Africa, and 2 human cases of infection were identified in Africa in 1981 and 2004 (3). Since 1996, when USUV was first detected outside Africa in a blackbird in Italy, the virus has been identified in mosquitoes and birds in several countries in Europe (4). In recent years, there has been increasing evidence for human infection with USUV (4), and USUV antibodies and USUV RNA have been detected in blood donors $(5,0)$.

A study published in 2016 characterized USUV phylogeny on the basis of available USUV strains from Africa and Europe (7). This study suggested that multiple introductions of USUV into central Europe from Africa could be confirmed and that Senegal was a possible origin for epizootics in central Europe.

$\mathrm{WNV}$ is the only flavivirus detected in Israel. WNV circulates in mosquitoes and birds in this country and was responsible for $\approx 1,400$ cases of human infections during 2000-2012 (8). Because Israel is located on a central bird migration path between Africa and Eurasia (9), circulation of USUV in this area is also plausible. We used the WNV national mosquito surveillance system in Israel as

Author affiliations: Chaim Sheba Medical Center, Ramat Gan, Israel (B. Mannasse, E. Mendelson, O. Mor, Y. Lustig); Medicine, Sackler School of Public Health, Tel-Aviv University, Tel-Aviv, Israel (E. Mendelson); Ministry of Health, Jerusalem, Israel (L. Orshan); Ministry of Environmental Protection, Jerusalem (U. Shalom, T. Yeger)

DOI: https://doi.org/10.3201/eid2310.171017 a source for identification of USUV strains circulating in mosquitoes in Israel during 2014-2015.

\section{The Study}

During 2014-2015, a total of 53,890 mosquitoes were trapped and grouped into 1,471 pools of $\leq 50$ mosquitoes/ pool. We tested RNA extracted from mosquito pools for USUV RNA by using quantitative reverse transcription PCR and specific primer-probe sets for the USUV nonstructural protein 5 (NS5) gene as described (10). We detected USUV RNA in 6 pools, 5 from 2015 and 1 from 2014. Although mosquito specimens were collected from trapping sites throughout Israel, all USUV RNA-positive pools were captured in northern Israel (Figure 1) and belonged to 3 mosquito species (Table).

We then performed amplification of an 845-nt sequence containing part of the envelope, membrane, and premembrane genes of USUV as described (11). Phylogenetic analysis showed that sequenced USUV strains from Israel clustered with a USUV strain isolated from Cx. neavei mosquitoes in 2007 in Senegal (Figure 2, panel A).

We then performed phylogenetic analysis of part of the NS5 gene because a previous study showed that this sequence exhibits a phylogenetic signal similar to the complete genome (7), which enables rapid characterization of circulating virus strains. Results (Figure 2, panel B) showed that USUV sequences from Israel closely resemble sequences of a USUV strain isolated from a bird in Germany in 2016, which was recently shown to belong to a putative novel USUV lineage called Europe 5 (11).

\section{Conclusions}

Despite its identification in 1959, USUV was not considered a potential public health concern until the early 2000s, when the first large USUV outbreak in birds occurred in Austria (10). Since that time, several human cases were identified in Europe and showed a correlation with increasing numbers of birds infected with USUV (4). It is possible that, similar to WNV outbreaks in Europe, the United States, and Israel during 1990-2010, which were occasionally preceded by large numbers of WNV infections in birds (12), USUV detection in birds and mosquitoes might be the first indication of future USUV outbreaks in humans. In this study, we identified 


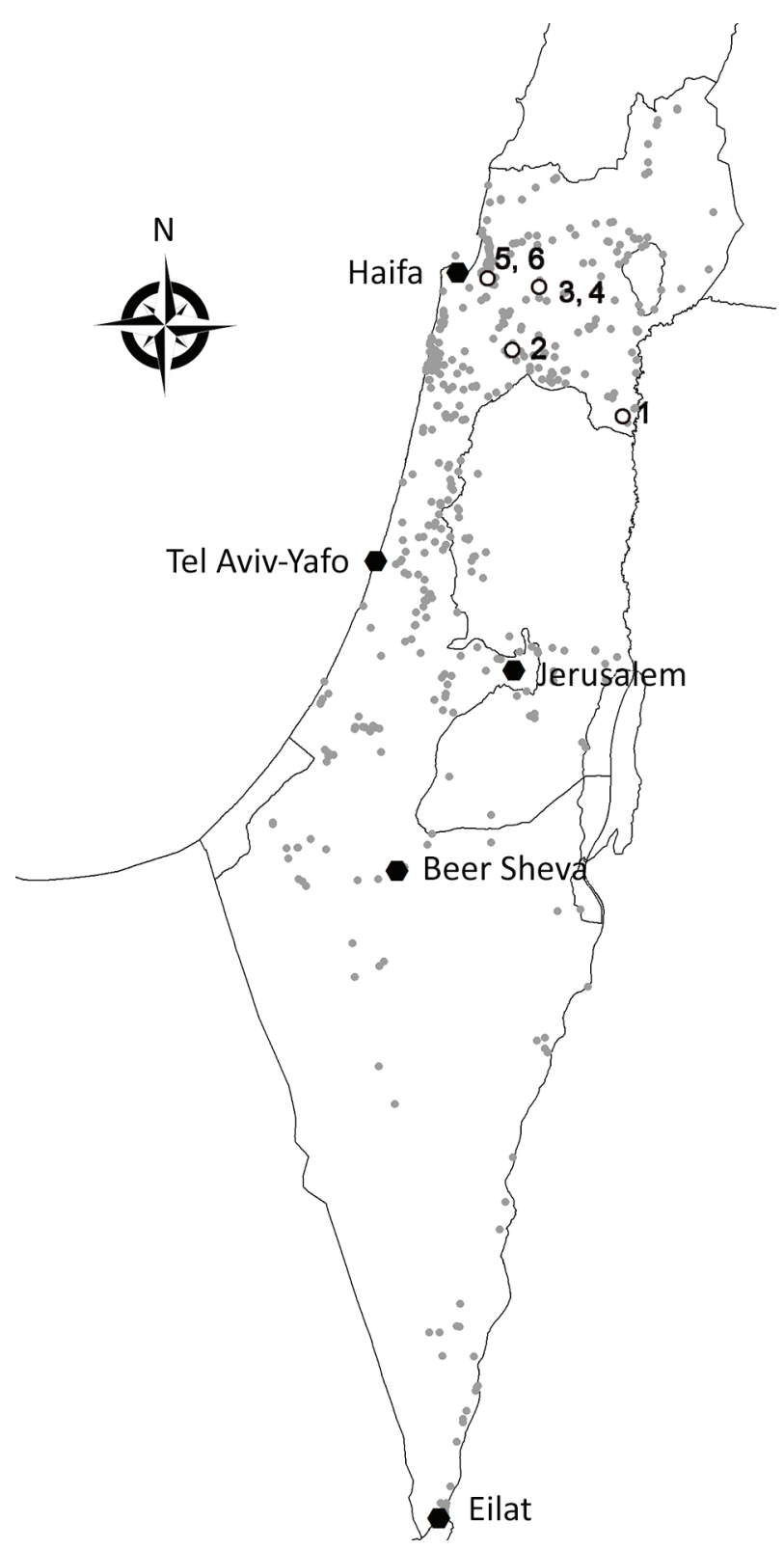

Figure 1. Spatial distribution of collection sites and Usutu virus infectious mosquitoes, Israel 2014-2015. Small gray circles indicate collection sites. Open circles and numbers indicate sites of Usutu virus-infected mosquitoes.

that USUV RNA is present in mosquitoes in Israel, which suggested that USUV infection in humans might also occur in Israel.

USUV RNA has been detected primarily in $C x$. pipiens and Cx. perexigus mosquitoes in Spain (13), in Cx. pipiens and $C x$. torrentium mosquitoes in Germany (14), and in Ae. albopictus and Cx. pipiens mosquitoes in Italy (15). Our finding of USUV RNA in $C x$. perexigus, $C x$. pipiens, and Ae. albopictus mosquitoes also suggests that USUV is transmitted by these 3 mosquito species in Israel.
Recently, reconstruction of the evolutionary history and dispersal of USUV has identified 6 distinct lineages of USUV. Nevertheless, Engel et al. concluded that limited numbers of USUV isolates from Africa and lack of data for countries located between Africa and Europe might obscure additional spatial movements (7).

Our phylogenetic analysis of the NS5 gene (Table) showed that USUV strains detected in Israel belong to the USUV Europe 5 lineage, mostly resembling a strain isolated in Germany in 2016. However, phylogenetic analysis on the basis of part of USUV structural proteins (Figure 1) indicates that virus strains from Israel are similar to USUV isolated from mosquitoes in Senegal in 2007, which was shown to be part of the Africa 3 lineage (11).

Because Israel is located on a bird migration path between Africa and Eurasia, USUV strains isolated in Germany, which are part of the Europe 5 and Africa 3 lineages, might have arrived from Africa through Israel, thus explaining the relative similarity of the strains in Israel to both lineages. Identification of more isolates from the Middle East and in-depth sequence analysis are needed to examine the geographic spread of the virus and further decipher its evolutionary history.

Our results showed that all 6 USUV-positive pools were captured in 3 mosquito species in northern Israel (Figure 1). Because most WNV-positive pools detected throughout Israel every year since 2000 belonged to the same mosquito species as those identified for USUV (16), the geographic discrepancy between circulation of WNV and USUV might be caused by different bird species carrying USUV or WNV. Future studies should examine the circulation of USUV in dead birds, as was demonstrated in several countries in Europe (11) and compare bird species carrying USUV with bird species carrying WNV in Israel and those carrying USUV in Europe.

Given the history of flaviviruses that were responsible for major outbreaks worldwide after decades of silent circulation, such as WNV and Zika virus, the accumulating evidence of increased activity of USUV in Europe is alarming. Therefore, investigation of USUV in mosquitoes in Israel is essential, not only because of public health concerns but also because of a need to understand the kinetics and penetration routes of USUV from Africa into Europe, Asia, and the Middle East.

This study was supported by internal sources of the Central Virology Laboratory, Chaim Sheba Medical Center, Ramat Gan, Israel.

Dr. Mannasse is a researcher at the National Zoonotic Viruses Reference Laboratory at the Ministry of Health, Tel Hashomer, Israel. Her research interests include clinical virology and phylogeny of arboviral diseases. 
Table. Analysis of mosquitoes for Usutu virus, northern Israel, 2014-2015*

\begin{tabular}{|c|c|c|c|c|c|}
\hline $\begin{array}{l}\text { Collection } \\
\text { site no. }\end{array}$ & Virus name & $\begin{array}{l}\text { Location of collection } \\
\text { site }\end{array}$ & $\begin{array}{c}\text { Date of sample } \\
\text { collection }\end{array}$ & Mosquito species & MLE \\
\hline 1 & Usutu, 269 m/2015/lsrael & Sdeh Eliahu & 2015 Jun 30 & Culex perexigus & 0.0047 \\
\hline 2 & Usutu, $550 \mathrm{~m} / 2015 / \mathrm{lsrael}$ & Midrach Stream & 2015 Sep 8 & Cx. perexigus & 0.0025 \\
\hline 3 & Usutu, 558 m/2015/lsrael & Yeftachel & 2015 Sep 8 & Cx. pipiens & 0.0138 \\
\hline 4 & Usutu, 569 m/2015/lsrael & Yeftachel & 2015 Sep 8 & Cx. pipiens & 0.0138 \\
\hline 5 & Usutu, 593 m/2015/lsrael & Haifa & 2015 Sep 21 & Aedes albopictus & 1 \\
\hline 6 & Usutu, $610 \mathrm{~m} / 2014 / \mathrm{Israel}$ & Kityat Ata & 2014 Oct 2 & Cx. pipiens & 0.0041 \\
\hline
\end{tabular}

*Virus-positive mosquitoes were identified by using real-time reverse transcription PCR. MLE for infection rate was calculated by using the EpiTools epidemiologic calculators method (http://epitools.ausvet.com.au/content.php?page = PPVariablePoolSize). MLE, maximum likelihood estimate.

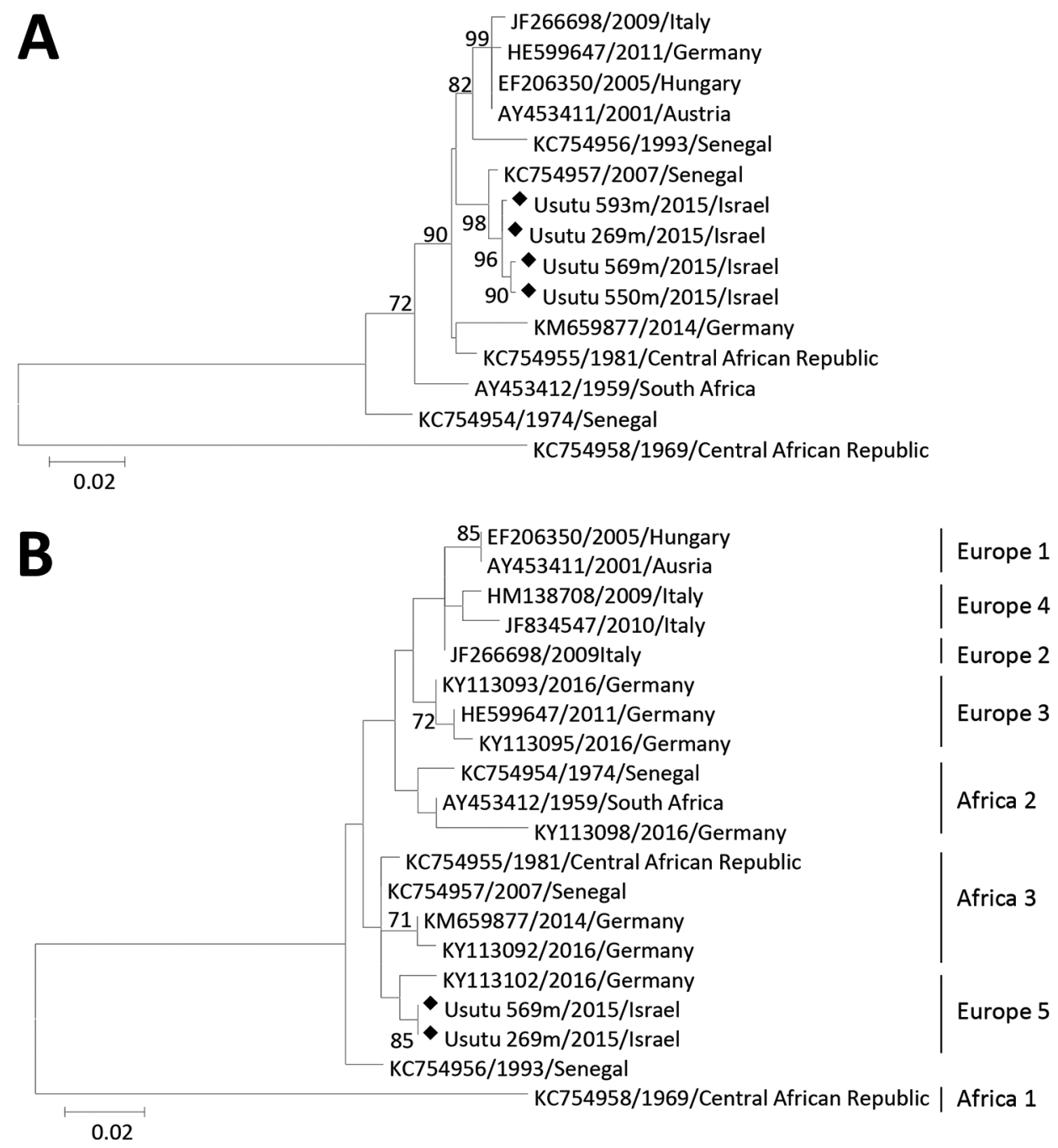

Figure 2. Phylogenetic tree of Usutu virus strains, Israel, 2014-2015. A) Structural protein genes. B) Nonstructural protein 5 genes. Analysis was conducted by using the maximum-likelihood method implemented in MEGA 6.0 software (http://www.megasoftware. net/). Robustness of branching pattern was tested by using 1,000 bootstrap replications. Percentage of successful bootstrap replicates is indicated at nodes (only values $>70 \%$ are shown). Diamonds indicate virus strains sequenced in this study. Reference strains are indicated by GenBank accession numbers and country and year of isolation. Scale bars indicate nucleotide substitutions per site.

\section{References}

1. Williams MC, Simpson DI, Haddow AJ, Knight EM. The isolation of West Nile virus from man and of Usutu virus from the birdbiting mosquito Mansonia aurites (Theobald) in the Entebbe area of Uganda. Ann Trop Med Parasitol. 1964;58:367-74. http://dx.doi.org/10.1080/00034983.1964.11686258
2. Nikolay B. A review of West Nile and Usutu virus co-circulation in Europe: how much do transmission cycles overlap? Trans R Soc Trop Med Hyg. 2015;109:609-18. http://dx.doi.org/10.1093/trstmh/trv066

3. Nikolay B, Diallo M, Boye CS, Sall AA. Usutu virus in Africa. Vector Borne Zoonotic Dis. 2011;11:1417-23. http://dx.doi.org/ 10.1089/vbz.2011.0631 
4. Vazquez A, Jimenez-Clavero M, Franco L, Donoso-Mantke O, Sambri V, Niedrig M, et al. Usutu virus: potential risk of human disease in Europe. Euro Surveill. 2011;16:19935.

5. Cadar D, Maier P, Müller S, Kress J, Chudy M, Bialonski A, et al. Blood donor screening for West Nile virus (WNV) revealed acute Usutu virus (USUV) infection, Germany, September 2016. Euro Surveill. 2017;22:30501. http://dx.doi.org/10.2807/1560-7917. ES.2017.22.14.30501

6. Gaibani P, Pierro A, Alicino R, Rossini G, Cavrini F, Landini MP, et al. Detection of Usutu-virus-specific IgG in blood donors from northern Italy. Vector Borne Zoonotic Dis. 2012;12:431-3. http://dx.doi.org/10.1089/vbz.2011.0813

7. Engel D, Jöst H, Wink M, Börstler J, Bosch S, Garigliany MM, et al. Reconstruction of the evolutionary history and dispersal of Usutu virus, a neglected emerging arbovirus in Europe and Africa. MBio. 2016;7:e01938-15. http://dx.doi.org/10.1128/mBio.01938-15

8. Anis E, Grotto I, Mendelson E, Bin H, Orshan L, Gandacu D, et al. West Nile fever in Israel: the reemergence of an endemic disease. J. Infect. 2014;68:170-5

9. Leshem Y, Yom-Tov Y. Routes of migrating soaring birds. Israel International Journal of Avian Science. 1998;140:41-52.

10. Weissenböck H, Kolodziejek J, Fragner K, Kuhn R, Pfeffer M, Nowotny N. Usutu virus activity in Austria, 2001-2002. Microbes Infect. 2003;5:1132-6. http://dx.doi.org/10.1016/ S1286-4579(03)00204-1

11. Cadar D, Lühken R, van der Jeugd H, Garigliany M, Ziegler U, Keller M, et al. Widespread activity of multiple lineages of Usutu virus, western Europe, 2016. Euro
Surveill. 2017;22:30452. http://dx.doi.org/10.2807/1560-7917. ES.2017.22.4.30452

12. Bin H, Grossman Z, Pokamunski S, Malkinson M, Weiss L, Duvdevani P, et al. West Nile fever in Israel 1999-2000: from geese to humans. Ann N Y Acad Sci. 2001;951:127-42. http://dx.doi.org/10.1111/j.1749-6632.2001.tb02691.x

13. Vázquez A, Ruiz S, Herrero L, Moreno J, Molero F, Magallanes A, et al. West Nile and Usutu viruses in mosquitoes in Spain, 2008-2009. Am J Trop Med Hyg. 2011;85:178-81. http://dx.doi.org/10.4269/ajtmh.2011.11-0042

14. Jöst H, Bialonski A, Maus D, Sambri V, Eiden M, Groschup MH, et al. Isolation of Usutu virus in Germany. Am J Trop Med Hyg. 2011;85:551-3. http://dx.doi.org/10.4269/ajtmh.2011.11-0248

15. Calzolari M, Bonilauri P, Bellini R, Albieri A, Defilippo F, Tamba M, et al. Usutu virus persistence and West Nile virus inactivity in the Emilia-Romagna region (Italy) in 2011. PLoS One. 2013;8:e63978. http://dx.doi.org/10.1371/ journal.pone. 0063978

16. Lustig Y, Hindiyeh M, Orshan L, Weiss L, Koren R, Katz-Likvornik S, et al. Fifteen years of mosquito surveillance reveals high genetic diversity of West Nile virus in Israel. J Infect Dis. 2016;213:1107-4. http://dx.doi.org/10.1093/infdis/ jiv556

Address for correspondence: Yaniv Lustig, Central Virology Laboratory, National Center for Zoonotic Viruses, Ministry of Health, Sheba Medical Center, Ramat Gan, Israel; email: yaniv.lustig@sheba.health.gov.il
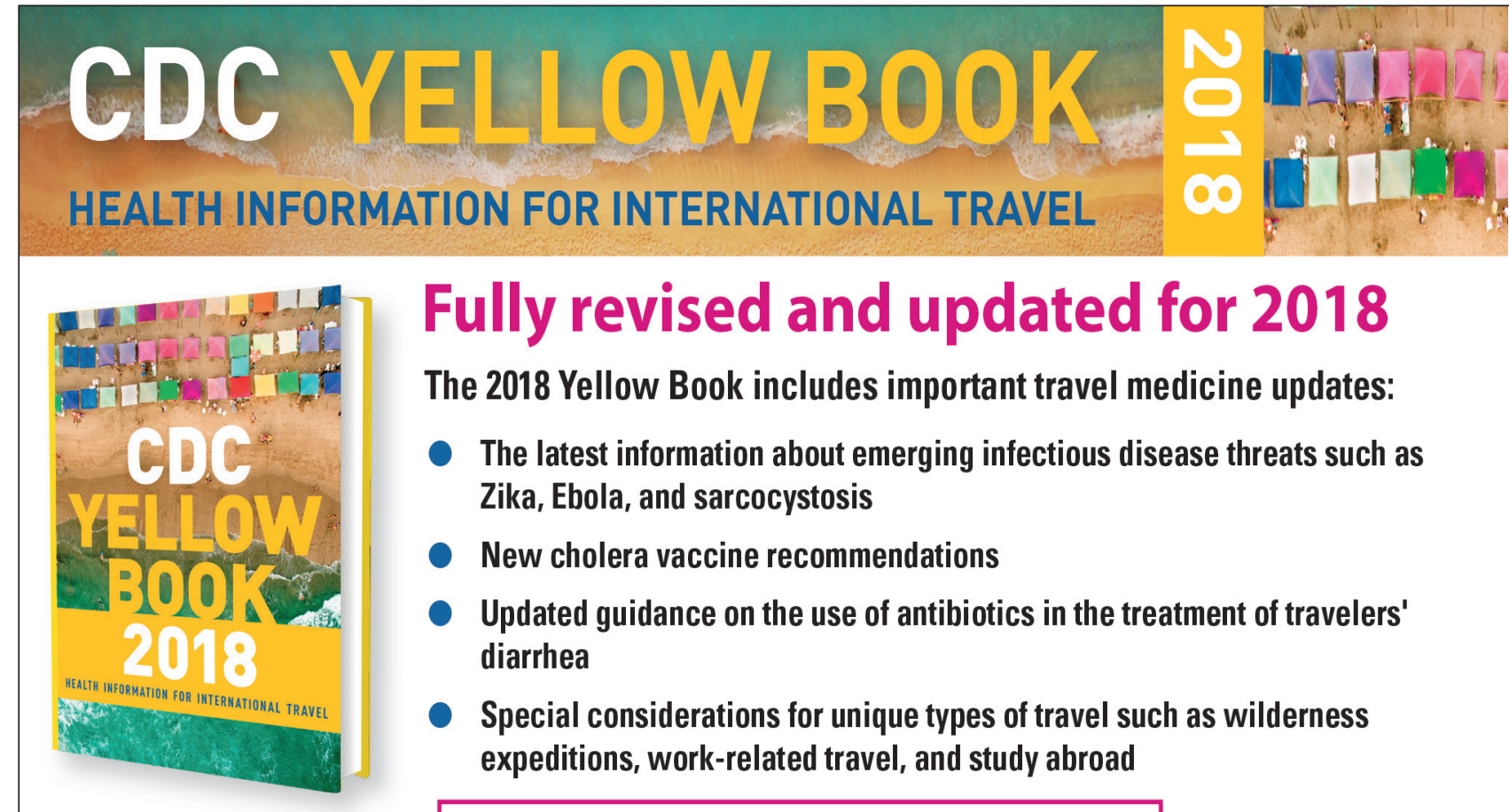

\section{Fully revised and updated for 2018}

\section{The 2018 Yellow Book includes important travel medicine updates:}

- The latest information about emerging infectious disease threats such as Zika, Ebola, and sarcocystosis

- New cholera vaccine recommendations

- Updated guidance on the use of antibiotics in the treatment of travelers' diarrhea

- Special considerations for unique types of travel such as wilderness expeditions, work-related travel, and study abroad

ISBN: 9780190628611 | \$49.95 | May 2017 | Paperback | 704 pages 